\title{
Immobilization of Free-ranging Red Foxes (Vulpes vulpes) with Tiletamine Hydrochloride and Zolazepam Hydrochloride
}

\author{
Alejandro Travaini and Miguel Delibes, Estación Biológica de Doñana, CSIC, Apdo. 1056, E-41080 Sevilla, Spain
}

ABSTRACT: We evaluated Zoletil on free-ranging red foxes (Vulpes vulpes) in Spain. Twentytwo pup and 49 adult wild-caught red foxes (Vulpes vulpes) were immobilized with a combination of tiletamine hydrochloride and zolazepam hydrochloride in a $1: 1$ proportion ( $\mathrm{Zo}$ letil). Mean ( $\pm \mathrm{SE}$ ) Zoletil doses were 10.57 $( \pm 0.41) \mathrm{mg} / \mathrm{kg}$ (range $=7.58-15.39 \mathrm{mg} / \mathrm{kg}, n$ $=22$ ) for pups and $10.51( \pm 0.33) \mathrm{mg} / \mathrm{kg}$ (range $=5.88-16.67 \mathrm{mg} / \mathrm{kg}, n=45)$ for adults. Mean induction and first recovery times for pups were $2.3( \pm 0.2)$ minutes (range $=1$ to 5 minutes) and $35.5( \pm 3.28)$ minutes (range $=18$ to 78 minutes), respectively. Mean induction and first recovery times for adults were $3.7( \pm 0.21)$ minutes (range $=2$ to 8 minutes $)$ and $35.4( \pm 2.22)$ minutes (range $=13$ to 90 minutes), respectively. We recommend Zoletil doses of $10 \mathrm{mg} / \mathrm{kg}$ for red foxes. For wild adult red foxes of unknown weight, an initial dose of 60 to $70 \mathrm{mg}$ Zoletil should be administered. This dose should allow about $\mathbf{4 0}$ minutes of handling time.

Key words: Immobilization, red fox, Vulpes vulpes, Spain, tiletamine, zolazepam, zoletil.

Tiletamine hydrochloride is a cyclohexane that produces a cataleptic state in which the eyes remain open with intact corneal and light reflexes (Domino, 1964; Seal and Kreeger, 1987). It is unavailable as a single product and usually is combined in equal proportions $(1: 1)$ with the diazepinone tranquilizer zolazepam (Gray et al., 1974). Tiletamine and zolazepam (Zoletil, Virbac S.A., Esplugues de Llobregat, Barcelona, Spain) anesthesia is characterized by retention of cranial, spinal, laryngeal, and pharyngeal reflexes. Zoletil has been used successfully to immobilize a wide variety of wild and captive animals (Shobert, 1987), including captive red foxes (Vulpes vulpes) (Kreeger et al., 1990a). However, the effectiveness and safety margins of $\mathrm{Zo}$ letil doses developed for captive red foxes have not been tested on wild foxes, which represent a wide spectrum of nutritional, physiological and also trapping stress conditions during immobilization (Kreeger et al., 1990b; White et al., 1991). Our objective was to evaluate Zoletil for immobilizing red foxes in the wild and to recommend effective Zoletil doses.

Twenty-two red fox pups (11 males, 11 females) and 51 adult red foxes (22 males, 29 females) were immobilized at Doñana National Park $\left(37^{\circ} 00^{\prime} \mathrm{N}, 06^{\circ} 30^{\prime} \mathrm{W}\right)$ from November 1990 through November 1992. Pups were excavated from their dens when they were 6 to $18 \mathrm{wk}$ old. Adults were captured using unpadded No. 2 Victor coilspring traps (Woodstream Corp., Lititz, Pennsylvania, USA) that were modified by protecting the steel jaws with soft material to reduce leg injuries. Recaptured animals were not included in the analyses in order to avoid pseudoreplication (Hurlbert, 1984). Captured foxes were placed in special cages and transported to the laboratory. Two to five hours after capture, pups and adults were physically restrained and injected intramuscularly in the hindquarters with a single dose of Zoletil. The dose chosen for each animal, following the recomendations of Kreeger et al. (1990a) for captive red foxes, was based on visual assessment of the individual's size and weight. After anesthetic induction, foxes were weighed and placed in right lateral recumbency. The eyes were covered with a cloth to avoid corneal damage and rectal temperature, respiration rates (breaths/ $\mathrm{min}$ ), and heart rate (beats/min) were monitored throughout the immobilization period. For comparison, reference values of red fox respiration and heart rate were estimated from their body weights (Stahl, 1967). Body temperature and heart rate reference values also were obtained from Kreeger et al. (1989). Ambient temperatures during immobilization ranged from 14 to $17 \mathrm{C}$ during autumn and winter, and from 18 to $23 \mathrm{C}$ during spring and sum- 
mer. Animals were left to recover in covered containers in dark, quiet areas. Induction time was defined as the time from injection of the anesthetic to loss of consciousness. First recovery time was defined as the time from loss of consciousness to first head movements. Foxes were released at the same place of capture the evening after the initial anesthetic. We used the two-sample $t$-test (Zar, 1984) for all comparisons. Acceptance of significant differences was set at $P<0.05$.

Zoletil doses ranged between 5.88 and $16.67 \mathrm{mg} / \mathrm{kg}$. For four adult females (two of them pregnant) a mean Zoletil dose of $8.99( \pm 0.48) \mathrm{mg} / \mathrm{kg}$ (range 7.61 to 9.78 $\mathrm{mg} / \mathrm{kg}$ ) was insufficient for total immobilization and complementary dosages of one half the initial dose were given. No other females in the sample were pregnant. There were no significant differences in mean Zoletil doses between sexes (pups: $P=0.31 ; t=1.03$; adults: $P=0.21, t=$ 1.26) or age classes (males: $P=0.88, t=$ 0.15 ; females: $P=0.90, t=0.13$; Table 1 ). Mean induction times were significantly shorter for pups than for adults (males: $P$ $=0.01, t=2.73$, females: $P<0.01, t=$ 3.07), were similar between sexes (pups: $P$ $=0.84, t=0.23$; adults: $P=0.44, t=0.77$, Table 1). We detected no significant differences in first recovery times between sexes (pups: $P=0.83, t=0.22$; adults: $P$ $=0.30, t=1.05$ ) or age classes (males: $P$ $=0.61, t=0.52$; females: $P=0.57, t=$ 0.58 ; Table 1).

We did not detect any excessive hypoor hyperthermia. Mean rectal temperature just after induction was $38.2( \pm 0.3) \mathrm{C}$ for pups (range $=37.3$ to $39.7 \mathrm{C}$ ) and 38.8 $( \pm 0.3) \mathrm{C}$ for adults (range $=38.2$ to 39.3 C). Mean rectal temperatures were about $1 \mathrm{C}$ lower than those of sleeping and active adult red foxes (Kreeger et al., 1989). Respiration rates increased slightly after immobilization (pups: $\bar{x}=51.8 \pm 3.6$ breaths/ min, range $=26$ to 96 breaths $/ \mathrm{min}$; adults: $\bar{x}=38.7 \pm 2.4$ breaths $/ \mathrm{min}$, range $=18$ to $74 \mathrm{breaths} / \mathrm{min}$ ) but declined to theo- retical reference levels (pups: 48 breaths/ min, adults: 35 breaths/ $\mathrm{min}$ ) within $75 \mathrm{~min}$ after induction (pups: $\bar{x}=45.7 \pm 10.6$ breaths/min, range $=25$ to 60 breaths/ min; adults: $\bar{x}=30 \pm$ breaths/min, range $=22$ to 38 breaths $/ \mathrm{min})$. Heart rates after immobilization had a similar pattern, initially averaging 232 and 218 beats/min for pups and adults, respectively, but declining to theoretical reference values (pups: 220 beats $/ \mathrm{min}$, adults: 163 beats $/ \mathrm{min}$ ) within 40 min after induction (pups: $\bar{x}=$ $217 \pm 4.6$ beats $/ \mathrm{min}$, range $=209$ to 228 beats/min; adults: $\bar{x}=198 \pm 10.4$ beats/ min, range $=180$ to 216 beats $/ \mathrm{min}$ ). Heart rates of adult foxes after $\mathbf{4 0}$ min induction were higher than those of sleeping and hunting foxes, similar to those of feeding foxes, and lower than those of running foxes (Kreeger et al., 1989).

In contrast to captive studies, the animals we used were free-ranging; thus, they probably represented a wide spectrum of nutritional and physiological conditions during immobilization. Additionally, stress due to capture and handling could affect induction and recovery times as well as heart rates, respiration rates, and body temperatures (Kreeger et al., 1990b; White et al., 1991). In spite of this, the combination of tiletamine hydrochloride and zolazepam hydrochloride achieved quick inductions and acceptable recovery times in free-ranging red foxes. In fact, dosages, induction times, and first recovery times were similar to those reported for captive red foxes (Kreeger et al., 1990a). This drug combination also provided good cardiac and respiratory support compared to the potential bradycardic and respiratory depressant effects of xylazine hydrochloride (Clark et al., 1982). This wide safety factor is valuable in field work, where animals rarely can be weighed or examined extensively before immobilization. We recommend a dose of $5 \mathrm{mg} / \mathrm{kg}$ tiletamine hydrochloride combined with $5 \mathrm{mg} / \mathrm{kg}$ zolazepam hydrochloride $(10 \mathrm{mg} / \mathrm{kg} \mathrm{Zo-}$ letil) for adult and pup red foxes. For un- 
TABLE 1. Statistics associated with red fox immobilization with a mixture of tiletamine hydrochloride and zolazepam hydrochloride (Zoletil) in Spain, 1990 to 1992.

\begin{tabular}{|c|c|c|c|c|c|c|c|c|c|c|c|}
\hline & \multirow{2}{*}{$\begin{array}{c}\text { Number } \\
\text { of } \\
\text { foxes }\end{array}$} & \multicolumn{2}{|c|}{ Mass (kg) } & \multicolumn{2}{|c|}{$\begin{array}{l}\text { Drug dosage } \\
(\mathrm{mg} / \mathrm{kg})\end{array}$} & \multicolumn{3}{|c|}{ Induction time (min) } & \multicolumn{3}{|c|}{ First recovery time (min) } \\
\hline & & Mean & $\mathrm{SE}$ & Mean & $\mathrm{SE}$ & Mean & $\mathrm{SE}$ & Range & Mean & $\mathrm{SE}$ & Range \\
\hline Adult females & 25 & 4.46 & 0.18 & 10.88 & 0.46 & 3.5 & 0.23 & $2-7$ & 33.3 & 2.54 & $14-63$ \\
\hline Adult males & 22 & 5.31 & 0.23 & 10.05 & 0.45 & 3.8 & 0.38 & $2-8$ & 37.9 & 3.85 & $13-90$ \\
\hline Adults combined & 47 & 4.84 & 0.16 & 10.51 & 0.33 & 3.7 & 0.21 & $2-8$ & 35.4 & 2.22 & $13-90$ \\
\hline Pup females & 11 & 1.57 & 0.31 & 10.99 & 0.80 & 2.4 & 0.20 & $2-4$ & 36.3 & 5.36 & $18-78$ \\
\hline Pup males & 11 & 1.27 & 0.26 & 10.14 & 0.20 & 2.3 & 0.36 & $1-5$ & 34.8 & 4.05 & $24-78$ \\
\hline Pups combined & 22 & 1.42 & 0.20 & 10.57 & 0.41 & 2.3 & 0.20 & $1-5$ & 35.5 & 3.28 & $18-78$ \\
\hline Total & 69 & 3.72 & 0.23 & 10.53 & 0.26 & 3.2 & 0.17 & $1-8$ & 35.4 & 1.82 & $13-90$ \\
\hline
\end{tabular}

- Dosage is expressed as mg Zoletil/kg body mass.

weighed, adult red foxes we recommend an initial dose of 60 to $70 \mathrm{mg}$ Zoletil. This should allow for a handling time of about $40 \mathrm{~min}$, sufficient to conduct most routine field procedures.

We thank the staff of the Donana Biological Reserve. R. Laffitte, A. Donaire and Isidrin captured the animals for this study. T. Rueda Gaona provided valuable technical assistance. Funding was provided by the Instituto para la Conservación de la Naturaleza and Dirección General de Ciencia y Tecnología (Project PB90-1018). Two anonymous referees substantially improved the original manuscript.

\section{LITERATURE CITED}

Clark, D. M., R. A. Martin, and C. A. Short 1982. Cardiopulmonary responses to xylazine/ ketamine anesthesia in the dog. Journal of the American Animal Hospital Association 18: 815821.

Domino, E. F. 1964. Neurobiology of phencyclidine (Sernyl), a drug with an unusual spectrum of pharmacological activity. International Review of Neurobiology 6: 303-347.

Gray, C. W., M. BuSh, AND C. BECK. 1974. Clinical experience using $\mathrm{CI}-744$ in chemical restraint and anesthesia of exotic specimens. Journal of Zoo Animal Medicine 5: 12-21.

Hurlbert, S. H. 1984. Pseudoreplication and the design of ecological field experiments. Ecological
Monographs 54, The Wildlife Society, Washington, D.C., pp. 187-211.

Kreeger, T. J., D. Monson, V. B. Kuechle, U. S SeAl, AND J. R. TeSTER. 1989. Monitoring heart rate and body temperature in red foxes (Vulpes vulpes). Canadian Journal of Zoology 67: 24552458.

, U. S. Seal, and J. T. Tester. 1990a. Chemical immobilization of red foxes (Vulpes vulpes). Journal of Wildlife Diseases 26: 95-98.

-, P. J. White, U. S. SEal, and J. R. Tester. 1990b. Pathological responses of red foxes to foothold traps. The Journal of Wildlife Management 54: 147-160.

Seal, U. S., and T. J. Kreeger. 1987. Chemical immobilization of furbearers. In Wild furbearer management and conservation in North America, M. Novak, J. A. Baker, M. E. Obbard, and B. Malloch (eds.). Ontario Trappers Association, Ontario, Canada, pp. 191-215.

SHOBERT, E. 1987. Telazol use in wild and exotic animals. Veterinary Medicine 82: 1080-1088.

STAHL, W. R. 1967. Scaling of respiratory variables in mammals. Journal of Applied Physiology 22: 453-460.

White, P. J., T. J. Kreeger, U. S. Seal, and J. R. TESTER. 1991. Pathological responses of red foxes to capture in box traps. The Journal of Wildlife Management 55: 78-80.

ZAR, J. H. 1984. Biostatistical analysis. Prentice-Hall International (UK) Limited. London, England, $718 \mathrm{pp}$

Received for publication 19 January 1994. 